\title{
Amyotrophic lateral sclerosis: improving care with a multidisciplinary approach
}

This article was published in the following Dove Press journal:

Journal of Multidisciplinary Healthcare

19 May 2017

Number of times this article has been viewed

\begin{abstract}
Anne Hogden'
Geraldine Foley ${ }^{2}$

Robert D Henderson ${ }^{3}$

Natalie James ${ }^{4}$

Samar M Aoun ${ }^{5}$

'Australian Institute of Health Innovation, Macquarie University, Sydney, NSW, Australia; ${ }^{2}$ Discipline of Occupational Therapy, School of Medicine, Trinity College Dublin, the University of Dublin, Republic of Ireland; ${ }^{3}$ Neurology, Royal Brisbane \& Women's Hospital, Brisbane, QLD, ${ }^{4}$ Motor Neurone Disease (MND) Service, Communication and Assistive Technology (CAT) Clinic, St Joseph's Hospital, St Vincent's Health Network, Sydney, NSW, ${ }^{5}$ School of Nursing, Midwifery and Paramedicine, Faculty of Health Sciences, Curtin University, Perth, WA, Australia
\end{abstract}

Correspondence: Anne Hogden

Australian Institute of Health Innovation, Faculty of Medicine and Health Sciences, Level I, 75 Talavera Rd, Macquarie University, NSW, Australia 2109

Tel +6I 298502417

Fax +6I 298502499

Email anne.hogden@mq.edu.au

\begin{abstract}
Amyotrophic lateral sclerosis (ALS) is a progressive neurodegenerative disease, leading to death within an average of 2-3 years. A cure is yet to be found, and a single diseasemodifying treatment has had a modest effect in slowing disease progression. Specialized multidisciplinary ALS care has been shown to extend survival and improve patients' quality of life, by providing coordinated interprofessional care that seeks to address the complex needs of this patient group. This review examines the nature of specialized multidisciplinary care in ALS and draws on a broad range of evidence that has shaped current practice. The authors explain how multidisciplinary ALS care is delivered. The existing models of care, the role of palliative care within multidisciplinary ALS care, and the costs of formal and informal care are examined. Critical issues of ALS care are then discussed in the context of the support rendered by multidisciplinary-based care. The authors situate the patient and family as key stakeholders and decision makers in the multidisciplinary care network. Finally, the current challenges to the delivery of coordinated interprofessional care in ALS are explored, and the future of coordinated interprofessional care for people with ALS and their family caregivers is considered.
\end{abstract}

Keywords: quality of life, interdisciplinary, interprofessional, palliative care, care coordination, motor neuron disease

\section{Introduction}

Amyotrophic lateral sclerosis (ALS), also known as motor neuron disease (MND), is a progressive and terminal neurodegenerative disease. The lifetime risk of developing the condition is 1:400. On average, death results within 2-3 years from symptom onset. ${ }^{1,2}$ Characterized by heterogeneous patterns of deterioration, presenting symptoms range from falls, limb weakness, communication, and swallowing difficulties to changes in mood, cognition, and behavior. ${ }^{1,3,4} \mathrm{Up}$ to $50 \%$ of people with ALS develop some degree of frontotemporal impairment. ${ }^{5,6}$ Patients may also be at risk of psychological problems such as depression and anxiety, linked to their disease experiences. ${ }^{4,7}$ No cure exists for ALS, and only a small number of treatments (eg, riluzole [pharmaceutical agent], non-invasive ventilation) delay death. Death usually results from respiratory failure. Care delivered and coordinated by multidisciplinary clinics (MDCs) specializing in ALS has been shown to extend survival and improve the quality of life for patients. ${ }^{9,10}$

To date, reviews of multidisciplinary (also known as interprofessional or interdisciplinary) ALS care have focused on symptom management and on the roles of health professionals in delivering care. ${ }^{11,12}$ However, such work does not illuminate the wider complexity of processes that underpin service delivery in multidisciplinary 
ALS care. Challenges to delivering multidisciplinary ALS care include: less than seamless coordination and transition of care between health care professionals across different sectors; patients' and family members' evolving expectations of care; ${ }^{13,14}$ and the lack of support available to health care professionals to deliver evidence-based care to patients and their families. ${ }^{15}$ Importantly, the roles of the patient, carer, and ALS support associations within the multidisciplinary team have not always been considered. A greater understanding of multidisciplinary care practices and of patients' and families' decision-making processes in ALS care can help generate more effective models of care. ${ }^{15}$

This review draws on a broad base of evidence pertaining to multidisciplinary ALS care, to help decipher how multidisciplinary care is best delivered to ALS patients and their family. First, multidisciplinary ALS care and the evidence that supports the effectiveness of multidisciplinary-based care in ALS are summarized and defined. Then, critical issues in ALS care and how MDCs are positioned to address them are considered. Finally, the challenges to the delivery of multidisciplinary ALS care and the benefits MDC care offers people and families living with ALS are outlined.

\section{What is multidisciplinary care in ALS?}

Multidisciplinary care in ALS encompasses the provision of care to the ALS patient and their family by a range of health care disciplines and support services. It is known that multidisciplinary care occurs when professionals who have different skills, knowledge, and experiences work together to achieve optimal care for patients and their families. Given the multitude of physical problems (eg, loss of mobility, respiratory failure, dysarthria, and dysphagia) and psychosocial problems (eg, depression, loss, bereavement, and family distress) posed by ALS, patients and their families engage with a variety of health care disciplines (Table 1). To comprehensively address ALS patients' broad range of needs, multidisciplinary care optimally includes medical practitioners in neurology, respiratory, gastroenterology, rehabilitation, and/or palliative care; allied health care professionals in physiotherapy, occupational therapy, speech and language pathology, nutrition and social work; and health professionals in specialist nursing, genetic counseling and psychology, including neuropsychology. ${ }^{10,16,17}$ Voluntary support services, mostly in the form of national and regional ALS/MND associations, also play an integral role in the

Table I Multidisciplinary approaches to symptom management

\begin{tabular}{|c|c|c|}
\hline Issue & Treatment options & Health care and support professionals involved \\
\hline Disease progression & Riluzole & Neurologist/rehabilitation physician \\
\hline \multirow[t]{3}{*}{ Breathing difficulty } & Assisted ventilation & Respiratory physician \\
\hline & & Respiratory therapist \\
\hline & & Nursing \\
\hline \multirow[t]{4}{*}{ Eating and drinking difficulties } & Gastrostomy & Gastroenterologist \\
\hline & & Dietitian \\
\hline & & Speech pathologist \\
\hline & & Nursing \\
\hline \multirow[t]{2}{*}{ Saliva management } & Medication & Neurologist/general practitioner/palliative care team \\
\hline & Botox & Neurologist \\
\hline \multirow[t]{3}{*}{ Mobility } & Mobility equipment & Physiotherapist \\
\hline & & Occupational therapist \\
\hline & & ALS association \\
\hline \multirow[t]{2}{*}{ Cognitive, behavior, and mood issues } & Counseling and support for patient and family & Neuropsychologist \\
\hline & & Psychologist \\
\hline \multirow[t]{3}{*}{ Self-care } & Assistive equipment & Occupational therapist \\
\hline & & Nursing \\
\hline & & ALS association \\
\hline \multirow[t]{3}{*}{ Communication } & Alternative communication devices & Speech pathologist \\
\hline & & Occupational therapist \\
\hline & & ALS association \\
\hline \multirow[t]{4}{*}{ Grief and loss } & Counseling and support for patient and family & Social worker \\
\hline & & Psychologist \\
\hline & & ALS association \\
\hline & & Palliative care team \\
\hline \multirow[t]{3}{*}{ Carer support } & Counseling and support for patient and family & Social worker \\
\hline & & ALS association \\
\hline & & Palliative care team \\
\hline
\end{tabular}

Abbreviation: ALS, amyotrophic lateral sclerosis. 
delivery of care to patients and their families. In developed countries, the voluntary sector has been shown to coordinate care for ALS patients and supplement the care that patients and their families receive from health services. ${ }^{18-20}$

Although multidisciplinary care is not limited to specific care settings or indeed to specialist care, the term "multidisciplinary" in ALS has become synonymous with care provided by MDCs. ${ }^{21-23}$ Activation of inter-service communication across different care sectors by specialized ALS clinics has proven to be essential for the delivery of high-quality care in ALS. ${ }^{18,24}$ Linkage between specialized MDCs and community-based services, general practitioner (or family physician), and palliative care services is required, so that by the terminal phase of the disease, many ALS patients and caregivers have experienced multiple encounters with different health care professionals across different health care sectors. Effective delivery of multidisciplinary care in ALS requires seamless collaboration, coordination, and transition between numerous health care professionals within and between disciplines, across a range of health care services and sectors.

Guidelines for the clinical management of ALS have been published in Europe, the UK, and the US. ${ }^{10,16,25}$ Health professional compliance with these guidelines has been assessed at specialized MDCs, to reveal reasonably high levels of implementation. ${ }^{26}$ However, patient adherence to health professionals' recommendations can vary. ${ }^{27}$ Ideally, patients should be reviewed every 2-3 months at an MDC, with the MDC team maintaining regular contact with the patient and family between visits. Patients should be followed by the same neurologist who in turn should liaise closely with the patient's primary care physician. Importantly, coordination of the patient's care requires effective communication between the MDC team, the palliative care team, and communitybased services. ${ }^{16,26}$

Standards in ALS care have been set by specialized ALS clinics. ${ }^{26,28}$ ALS MDC-based care in the Netherlands has resulted in improved quality of life for patients and greater provision of aids and equipment to patients. ${ }^{29}$ Specialized ALS MDCs in Italy have increased survival and reduced hospital admissions and length of hospital stay for patients. ${ }^{30}$ Traynor et $\mathrm{al}^{31}$ found improved survival of 7.5 months, with 1 -year mortality being reduced by $30 \%$ for patients attending a national ALS clinic in Ireland. Extended survival rates have also been identified in a more recent Irish study focused on the effects of an ALS MDC on patient survival. ${ }^{32}$ The aforementioned studies reported better outcomes when compared to care that was not multidisciplinary; although, as comparison groups are not always well matched, generalized comparison is difficult. Zoccolella et $\mathrm{al}^{33}$ found that MDC care did not improve survival when compared to general neurology care. However, respiratory and nutritional interventions were low for these groups, and the MDC did not link directly to community-based services or palliative care services. ${ }^{33}$ It is likely that survival in ALS is influenced by the complex decision-making processes that occur in the multidisciplinary setting, rather than by the effects of symptomatic interventions alone. ${ }^{32}$

\section{Models of multidisciplinary care in ALS}

A coordinated, interprofessional approach to address the needs of ALS patients is represented in several models of care. ${ }^{21-24,34-36}$ These models share a patient-centered approach $^{37}$ and recognize that patients and their family members are key stakeholders in care and have active roles in the decision-making process. ${ }^{38,39}$ Family caregivers are central to the care and support of people with ALS, and they too encounter multiple losses in their caring role. Caring for a person with ALS can be physically and emotionally demanding for family members, ${ }^{40-42}$ and family caregivers who feel unsupported by health care professionals can experience increased caregiver strain. ${ }^{41}$ Although family caregivers tend to have a pivotal role in the provision of informal care and support to the patient, ${ }^{43}$ ALS family caregivers' needs can be overlooked by service providers. ${ }^{44,45}$ As for patients, family caregivers in ALS navigate the challenges posed by ALS and assume high levels of responsibility within the ALS care triad (the person with ALS, the family carer, and the health care provider). ${ }^{44,46}$

Multidisciplinary ALS care is dynamic and has the capacity to adapt to different healthcare contexts. Multidisciplinary ALS care can be provided by publicly or privately funded organizations delivering neurology, rehabilitation, and palliative care services, across primary, secondary, and tertiary care sectors. In many cases, patients and families work with clinicians from different multidisciplinary teams that form their broader ALS-specialized multidisciplinary service - a team within a team. For example, patients may engage with neurology and palliative care-based health professionals who interface at key points along the patient's trajectory. Care in ALS is most effective when coordinated between specialized MDCs, the community-based sector (including primary care), and palliative care teams. ${ }^{16}$ Corr et $a l^{18}$ have shown that close liaison between a specialized ALS clinic, community-based services (eg, allied health care professionals, physicians, and homecare services), and the voluntary sector (ie, the local 
ALS association) can render effective care for ALS patients. In addition, there are potential benefits of specialized nurse coordinators in a liaison role, particularly in the later stages of the disease. ${ }^{47}$

Multidisciplinary care in ALS is appropriate throughout the disease course (ie, diagnostic, disability, pre-terminal, and terminal phases $)^{24}$ and is rendered via rehabilitative and palliative approaches to care. "Rehabilitation" is understood in the context of interventions that can assist patients and their families to adapt to the physical and psychological challenges of living with ALS (ie, counseling, social support, alleviation of spasticity, provision of orthotics and appliances, and training in assistive technology), rather than regain the physical loss or remedy the cognitive change encountered by ALS patients. ${ }^{21,48,49}$ The term "palliative" infers an approach that seeks to alleviate physical, psychological, and existential distress.

\section{The role of palliative care in multidisciplinary ALS care}

Palliative care is essential for patients with ALS and their families to ensure their symptoms and issues are clearly identified and appropriately managed ${ }^{50}$ and to improve the quality of life for patients and their carers. ${ }^{14,51}$ In ALS, palliative care is appropriate from the time of diagnosis, ${ }^{16,52}$ especially as the extended duration between symptom onset and diagnosis means many patients are severely disabled by the time they are diagnosed. Members of the palliative care team, led by a specialist palliative care physician, may work in a multidisciplinary context within their own care setting (such as community or home-based palliative care, specialized inpatient and outpatient palliative care facilities). The palliative care team is part of the wider multidisciplinary care approach that traverses the different care sectors involved in delivering services to ALS patients and their families.

However, few palliative care frameworks have been developed to guide active palliative care engagement in ALS. ${ }^{51}$ There may be issues within and between the acute care, rehabilitation, and palliative care teams involved, due to the differing attitudes and philosophies of patient care. It is important that there is awareness of and negotiation around these issues to enable well-coordinated care and seamless transition between services. ${ }^{53}$ Nonetheless, the palliative approach in ALS care can accommodate the evolving needs of the patient and their family ${ }^{2,51}$ (Figure 1). The palliative care needs of patients and their family can vary and fluctuate. The involvement of specialist teams may be episodic, occurring at times of change, crisis, or decision making - for example, at diagnosis, when discussing gastrostomy or ventilatory support,

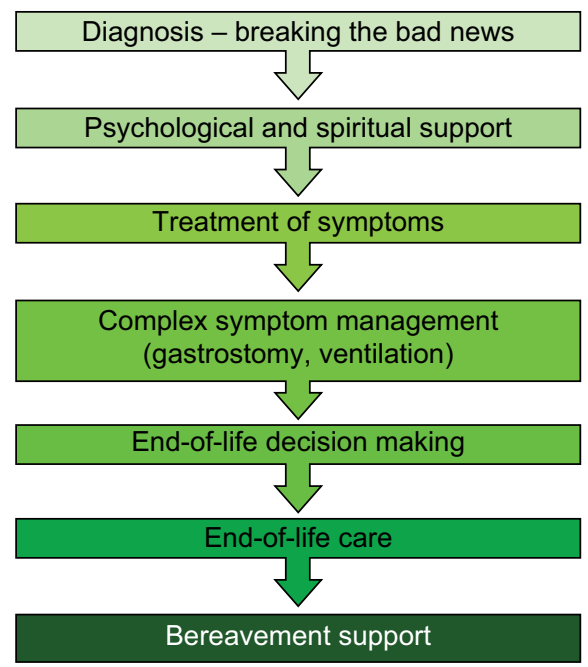

Figure I Development of a palliative approach in ALS.

Note: Reprinted from Lancet, 369(9578), Mitchell JD, Borasio GD, Amyotrophic lateral sclerosis, 203I-204I, Copyright (2007), with permission from Elsevier. ${ }^{2}$

Abbreviation: ALS, amyotrophic lateral sclerosis.

or when change in patient cognition or behavior occurs, which may impact on the timing or appropriateness of decisions at the end of life ${ }^{35,51}$ (Figure 2). Overall, optimal palliative management of people with ALS and their family requires integrated MDC and palliative- and community-based intervention. ${ }^{54,55}$

\section{What are the costs of formal and informal ALS care?}

Costs associated with ALS care have been evaluated in a number of countries. ${ }^{56-62} \mathrm{MDC}$-based care has been cost-effective

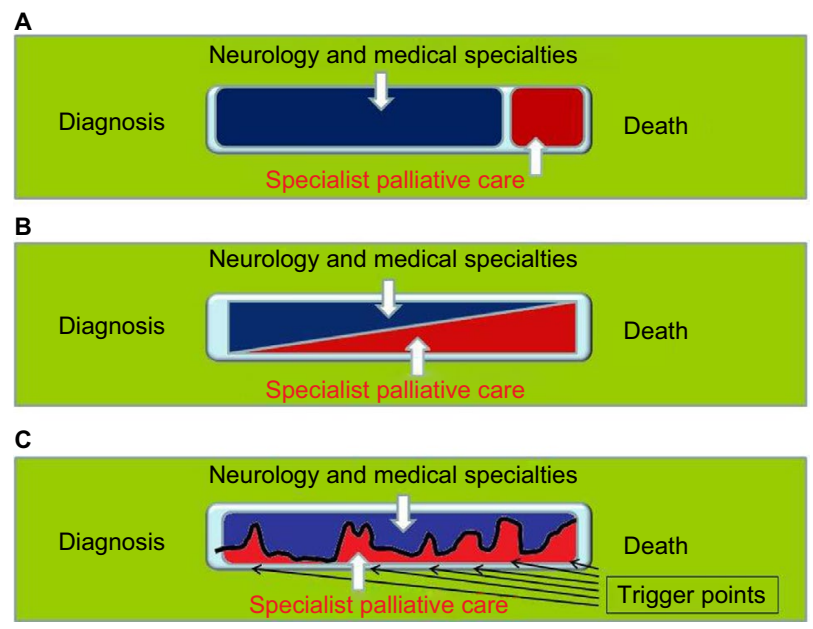

Figure 2 Involvement of palliative care in ALS and other neurological diseases. Notes: (A) The traditional model of late involvement of specialist palliative services. (B) The model of early and increasing involvement of specialist palliative services. (C) The model of dynamic involvement of palliative services based on trigger points. Reproduced from Bede P, Hardiman O, O'Brannagain D. An integrated framework of early intervention palliative care in motor neurone disease as a model to progressive neurodegenerative diseases. Poster presented at: 7th European ALS Congress; May 22-24, 2009; Turin, Italy ${ }^{35}$ which was originally adapted from Maddocks I, Brew B, Waddy H, Williams I, Palliative Neurology, Cambridge University Press, 2005.98 Abbreviation: ALS, amyotrophic lateral sclerosis. 
in terms of reducing rates of patient hospitalization. ${ }^{30}$ Moreover, van der Steen et $\mathrm{al}^{56}$ have shown that the cost of specialized care provided and coordinated by ALS MDCs was no more than the cost of managing ALS through non-specialist services. However, the true cost-effectiveness of formal ALS care is difficult to determine as patients may engage with multiple health care professionals prior to diagnosis. ${ }^{63,64}$

Connolly et $\mathrm{al}^{57}$ quantified the health and social care costs of ALS in Ireland and found that the largest proportion of costs $(72 \%)$ arose in community-based care. Seven percent of all costs were attributable to aids and appliances, and only $21 \%$ of costs were attributable to services at the national ALS clinic in Ireland. Higher health and social care costs were associated with the use of non-invasive ventilation and gastrostomy and with shorter survival. Depending on the health care system in question, out-of-pocket expenses can also be substantial in ALS care. ${ }^{60,61}$

A review of the economic impact of ALS has also been undertaken. ${ }^{65}$ Standardized to the 2015 USD, Gladman and Zinman $^{65}$ identified significant variation across 12 developed health care systems in the annual cost of care for the ALS patient. Annual cost of care ranged from $\$ 13,667$ in Denmark to as high as $\$ 69,475$ in the US. Health care costs associated with ALS were also higher than that of other neurological conditions. Analysis of the social economic costs of ALS in Spain $^{58}$ found that costs of informal care (ie, non-paid care including care provided by family) extended well beyond the cost of multidisciplinary care. Furthermore, an economic analysis of costs in ALS in Australia ${ }^{59}$ identified that the costs of informal care and support services (eg, aids and appliances) exceeded direct health care system costs (ie, care facility and health care professional costs). Moreover, economic disadvantage through productivity loss is shouldered by family carers, with the Australian economic analysis estimating this cost to be AUD 4.4 million. ${ }^{59}$

\section{Critical issues in multidisciplinary ALS care}

Three critical points in ALS patients' care journey shape their health care outcomes and their quality of life. These critical points include the timing and delivery of the diagnosis, the accessing of MDC care, and the timing of decisions surrounding symptom management and end-of-life care.

\section{Timing of the diagnosis}

Delays in obtaining a diagnosis in $\operatorname{ALS}^{66,67}$ can result in adverse consequences for patients. ${ }^{4,68}$ Diagnostic delay can occur for several reasons, such as inefficient referral pathways within health care systems, patients not fully recognizing their own symptoms, and a lack of familiarity with ALS among
non-ALS physicians. ${ }^{63,68,69}$ Delays have arisen because of late referral to specialist investigation, inappropriate referral to non-specialist services, and underrecognition of early symptoms by health care professionals. ${ }^{63,68,69}$ Within the secondarycare sector alone, diagnostic delays can occur when patients are referred by non-specialist physicians (ie, physicians other than neurologists) to other non-specialist physicians before referral onward to neurologists who specialize in ALS. ${ }^{69}$ Indeed, in a US-based study of diagnostic timelines in ALS, ${ }^{66}$ more than half of the participants had received an alternative diagnosis before they received a diagnosis of ALS, and each patient had seen multiple physicians before their diagnosis was confirmed. The average diagnostic timeline in ALS has been shown to range between 10 months and 18 months. ${ }^{16,63,66,67,69}$ Notwithstanding the complex referral trajectory encountered by ALS patients and their families, a fast-track system for diagnosing ALS at a specialized ALS center reduced diagnostic delays when compared to general neurology diagnostic care pathways. ${ }^{69,70}$ In addition, a "red flag" tool has also been developed in the UK to facilitate timely referral to specialist services. ${ }^{71}$

\section{Giving and receiving the diagnosis}

The giving and receiving of a terminal diagnosis is a difficult and distressing event for health professionals, patients, and families. In a recent Australian-based study, neurologists at ALS MDCs were judged by patients and family caregivers as doing better in disclosing the diagnosis when compared to neurologists in non-MDC settings' ${ }^{13,44,72}$ Neurologists based in MDC settings adhered more to international guidelines ${ }^{16}$ on disclosure than did neurologists from non-MDC settings. ${ }^{72}$ Of note, the time spent giving the diagnosis to patients was significantly longer for the MDC group - an average of 23 minutes for non-MDC clinicians and twice as long for those in MDCs (45 minutes). ${ }^{72}$ Family members were more likely to be present when the diagnosis was disclosed by MDCbased neurologists. Moreover, coordinated and interprofessional care was more likely to be facilitated by MDC-based neurologists. ${ }^{72}$

\section{Accessing specialized ALS services}

ALS patients have reported difficulty accessing interdisciplinary care in community-based settings without assistance from specialized MDCs. ${ }^{73}$ However, patients' attendance at MDCs varies within and between countries. Population-based comparative studies between specialized ALS clinics and general neurology clinics in Italy ${ }^{30,33}$ show that between $43 \%$ and $66 \%$ of people with ALS access specialized ALS clinics. Approximately $80 \%$ of ALS patients in Ireland attend one 
national ALS clinic ${ }^{32}$ and an estimated $85 \%$ of patients with ALS in the Netherlands attend the national ALS Centre. ${ }^{74}$ In Australia, patients attend one of 10 clinics located in six state capitals; however, rates of attendance are undocumented. A survey of ALS patients in the US revealed that $78 \%$ of respondents attended a specialized ALS MDC, ${ }^{75,76}$ whereas in the UK it is estimated that $70 \%$ of ALS patients access MDCs. ${ }^{77}$

Stephens et al's study of multidisciplinary ALS clinic use in the $U^{76}$ reported patient perspectives on the benefits and barriers to attending specialized ALS clinics. Access to integrated care and the potential to engage in research, including clinical trials, were valued by patients. However, the long duration of MDC visits and patients' reluctance to travel long distances to MDCs also limited the attendance for some patients. The European Federation of Neurological Societies (EFNS) guidelines recommend that more frequent reviews for patients at MDCs in the months following diagnosis or in the later stages of disease may be needed, with less frequent review if the disease is progressing slowly for patients. ${ }^{16}$ In the US, 3-monthly visits by ALS patients to large MDCs are common. ${ }^{62}$ Nevertheless, for a proportion of patients, an MDC visit may be a single occurrence only.

Few large-scale studies have captured the journey that patients and their families travel from symptom onset to specialized multidisciplinary ALS care. Galvin et al ${ }^{63}$ conducted a retrospective exploratory study that tracked ALS patients' paths to a specialized ALS clinic. The average time from symptom onset to attendance at the MDC was 19 months. The first point of contact for ALS patients in health care services was invariably a general practitioner. Even so, patients also had multiple consultations with other services in primary and secondary care (eg, accident and emergency, other neurology services, and individual allied health care professionals) before they received a diagnosis or attended the clinic. Patients' consultations with disciplines prior to diagnosis or attendance at the MDC clinic tended not to be coordinated between disciplines. However, most MDCs are located in metropolitan regions and in large tertiary hospitals or centers and may not be accessible to some patients and their family. Moreover, health care organization funding may limit the availability of services to patients living outside their catchment area or geographical boundary. Patients who live a long distance from an MDC may be at a disadvantage in the latter stages of the disease, particularly when fatigue and mobility restrictions increase for them. ${ }^{76}$

The use of tele-health has the potential to offset some of the logistical difficulties associated with accessing specialized ALS clinics. Where patients are unable to physically access the MDC, tele-health can enable the MDC team to interface with patients and their family in the home environment. ${ }^{77,78}$ In addition, tele-health has the potential for local and community-based services to engage with the MDC in real time and to partner the MDC in the decision-making process. ${ }^{77,78}$ In the case of respiratory care, the benefits of tele-health for ALS patients have been reported. ${ }^{79,80}$ The setting and monitoring of invasive ${ }^{81}$ and non-invasive ventilation $^{82}$ where the parameters for clinical assessment can be downloaded from a remote location have strong application in a tele-health model of care. Tele-health can be provided to ALS patients in conjunction with or as follow-up to face-to-face visits with patients. ${ }^{80}$ Continuity of care and of symptom management are specific advantages of telehealth for ALS patients, ${ }^{78}$ and both patients and clinicians in ALS care have been shown to be receptive to tele-health ${ }^{80,81}$ One study showed that tele-health for ALS care impacted positively on health care utilization, patient survival, and patient functional status. ${ }^{82}$ Nurse-led tele-health may also be beneficial if initiated in the later stages of the disease. ${ }^{79}$ Further investigation into the application of tele-health in multidisciplinary rehabilitation and palliative care services for ALS patients and their families is required.

\section{Timing of decisions for symptom management and end-of-life care}

Patients (and families) are often required to make decisions for symptom management and quality of life as the disease progresses. ${ }^{83-85}$ Decisions are made with multiple health professionals and require cross-sector coordination. Decisions for life-extending or symptomatic measures (eg, gastrostomy, invasive ventilation and non-invasive ventilation), as well as end-of-life care, are complex. ${ }^{16,17}$ Successful outcomes can depend upon the timing of interventions. Patients are encouraged to consider their options and make choices about care in a timeframe that enables successful outcomes for both patients and their family caregivers. The consequences of avoiding decision making, for example, for nutrition/ hydration or respiratory distress, can impact the patient's health and quality of life. However, some patients may also feel conflicted by having to make decisions about care. ${ }^{86,87}$ Patients may not feel ready for procedures or equipment that signal further deterioration in their condition and that which would increase their dependence on family members. Lifeextending measures may also conflict with patients' and family caregivers' long-held values pertaining to end-of-life care.

The ALS MDC can offer patients and their family caregivers a supportive setting when discussing treatment decisions. ${ }^{86,87}$ A model to guide decision making in ALS that incorporates patients and their carers in the decision-making 
processes of care has been developed from the MDC setting. ${ }^{22,38}$ This model facilitates shared decision making with patients and their carers and situates patients and their carers within the multidisciplinary network of care. Allowing sufficient time and space for patients and their carers to digest information about care, deliberate on the options available to them, and make decisions about how they would like to engage with multidisciplinary care are key components of inclusive decision making in multidisciplinary ALS care. ${ }^{22}$ The ALS MDC setting can be a suitable forum for a multidisciplinary team to collectively engage with patients and their family in shared decision making pertaining to symptom management and quality-of-life choices. ${ }^{87}$

\section{Developments in multidisciplinary ALS care}

\section{The evolving multidisciplinary ALS care team}

As models of care evolve to keep pace with the new understanding of this complex disorder, the multidisciplinary ALS care team has expanded accordingly. ${ }^{10,16,17,42,88}$ Recent additions to the multidisciplinary ALS care team have included neuropsychologists, genetic counselors, and case managers. A frontotemporal syndrome occurs in a substantial proportion of ALS patients, a subgroup of whom present with frontotemporal dementia. ${ }^{89}$ Expert consensus is that care provision in ALS should include interventions directed toward the management of cognitive and behavioral impairment in ALS, including educational and support services for family carers on how best to support and care for ALS patients who have cognitive or behavioral impairment. ${ }^{10,16}$ In this context, neuropsychologists make an important contribution to the care of ALS patients and their caregivers.

The identification of multiple novel genes in ALS and the newly recognized link between ALS and frontotemporal dementia have resulted in the need to incorporate genetic counseling into multidisciplinary ALS care. ${ }^{16,90,91}$. However, ALS patients have reported difficulty accessing genetic testing..$^{92}$ Indeed, studies have yet to estimate the proportion of the ALS population that engage with genetic testing and genetic counseling. Genetic counseling in ALS may pose significant challenges to patients, family, and health professionals, in the context of the ethical, legal, and psychological dimension surrounding disclosure, and the impact the disclosure can have on the wider family. ${ }^{91}$ Nonetheless, ALS patients have reported high levels of interest in genetic testing. ${ }^{92}$

The role of case management in ALS, in which designated professionals work collaboratively with patients and their families, guiding and supporting them through the different phases of care, has been examined. ${ }^{42,88}$ Initially, a Dutch randomized control study on case management in $\mathrm{ALS}^{88}$ showed that case management conferred no benefit to patient health-related quality of life or to caregiver strain when compared to normal care. However, a qualitative investigation of patients' and their caregivers' perceptions of the same service ${ }^{42}$ identified that ALS patients and their families were receptive to case management and that they valued the additional emotional support available to them from a case manager. Patients' and caregivers' own coping styles and their satisfaction or dissatisfaction with usual care influenced how receptive they were to case management. ${ }^{42}$

\section{Benefits and challenges to health professionals in delivering coordinated and interprofessional ALS care}

Alongside the benefits that patients and their family encounter in multidisciplinary ALS care are advantages to health care professionals who work within the MDCs. Health professionals gain experience and expertise in ALS care, ${ }^{93}$ learning from patients and family caregivers when supported in a clinical environment dedicated to ALS care. Although patient satisfaction with MDC services is in general high, ${ }^{62}$ the provision of multidisciplinary-based care to people with ALS and their families can have a significant impact on health care professionals who render and coordinate the care. Health professionals in ALS care can experience varying degrees of stress related to their clinical work, ${ }^{94}$ and the emotional burden encountered by health care professionals caring for people with ALS can be severe. ${ }^{55}$ Feelings of stress and anxiety can arise for physicians while delivering the diagnosis and prognosis, ${ }^{72}$ whereas withdrawal of treatments can pose ethical and psychological dilemmas for health care professionals who provide end-of-life care. ${ }^{95,96}$ In an Australian-based study, ${ }^{72} 70 \%$ of neurologists surveyed found communicating the diagnosis of ALS "very to somewhat difficult," whereas $43 \%$ of them found responding to patients' and family members' reaction to the disclosure "very to somewhat difficult." Sixty-five percent of neurologists experienced "high to moderate" stress and anxiety during the disclosure. Physicians reported the challenges surrounding the need to be honest without taking away hope, dealing with the patient's emotional reaction to the diagnosis, and judging the optimal amount of time to deliver the diagnosis. The reasons for experiencing these difficulties included the lack of effective treatments in ALS, fear of causing distress to patients, and fear of not having all the answers for patients.

Support and education systems need to be developed that help health care professionals to manage the emotional and moral distress that they encounter in ALS practice. ${ }^{97}$ Connolly 
et $\mathrm{al}^{55}$ called for a recognition of the emotional burden that health care professionals encounter when caring for people with ALS, "with structures and procedures developed to address compassion, fatigue, and the moral and ethical challenges related to providing end-of-life care" (p. 435). Support from health care organizations is required to ensure that health professionals in multidisciplinary ALS care are financially and emotionally supported in their role as service providers. ${ }^{87}$

\section{Conclusion}

Specialized multidisciplinary care is more than a means of delivering appropriate symptom management to ALS patients. This review has identified that coordinated and interprofessional care that meets the expectations of ALS patients and their families is a combination of multiple facets of care. These include care underpinned by an increasing evidence base; service providers applying a patient- if not family-centric approach to care; strong inter-service communication; and an interprofessional team resourced and funded to provide expert care to patients and their family caregivers.

MDC-based care in ALS offers benefits and challenges to patients, carers, and health professionals. Importantly, the evidence in ALS care has been fueled by research undertaken and coordinated by MDCs. ${ }^{23,29,32}$ The links between interprofessional practice and clinical research are strengthened when frontline clinicians, patients, and carers are able to contribute to our understanding of how multidisciplinary ALS care improves patient care and quality of life.

Although MDCs offer an optimal model of coordinated interprofessional care, the transition of care between care settings remains a concern. Strategies toward standardizing care delivery for patients and carers may help to reduce the wide-ranging experiences from the very good to the not so good. The development of best practice guidelines and of protocols to improve inter-service communication skills among health care professionals may alleviate the emotional burden of service providers and the distress that patients and their family encounter when confronted with poorly coordinated care.

Finally, patients' attendance rates at specialized ALS MDCs show that a significant portion of ALS patients are not able, or choose not, to access MDC care. Stronger links between specialized ALS MDC services, general neurology, and primary care services could improve the quality of care for patients being managed in their own community and increase the expertise of practitioners outside the current MDC network. An improved understanding among the wider health care community of how MDC teams deliver care will assist the development of clinical pathways that connect MDC and non-MDC services. A network that is accessible to all clinical services caring for ALS patients will improve patient care, service transition, and health care professionals' understanding of ALS.

\section{Disclosure}

The authors report no conflicts of interest in this work.

\section{References}

1. Kiernan MC, Vucic S, Cheah BC, et al. Amyotrophic lateral sclerosis. Lancet. 2011;377(9769):942-955.

2. Mitchell JD, Borasio GD. Amyotrophic lateral sclerosis. Lancet. 2007;369(9578):2031-2041.

3. Lillo P, Garcin B, Hornberger M, Bak TH, Hodges JR. Neurobehavioral features in frontotemporal dementia with amyotrophic lateral sclerosis. Arch Neurol. 2010;67(7):826-830.

4. Caga J, Ramsey E, Hogden A, Mioshi E, Kiernan MC. A longer diagnostic interval is a risk for depression in amyotrophic lateral sclerosis. Palliat Support Care. 2015;13(4):1019-1024.

5. Lillo P, Mioshi E, Zoing MC, Kiernan MC, Hodges JR. How common are behavioural changes in amyotrophic lateral sclerosis? Amyotroph Lateral Scler. 2011;12(1):45-51.

6. Lillo P, Savage S, Mioshi E, Kiernan MC, Hodges JR. Amyotrophic lateral sclerosis and frontotemporal dementia: a behavioural and cognitive continuum. Amyotroph Lateral Scler. 2012;13(1):102-109.

7. Lule D, Hacker S, Ludolph A, Birbaumer N, Kubler A. Depression and quality of life in patients with amyotrophic lateral sclerosis. Dtsch Arztebl Int. 2008;105(23):397-403.

8. Chen D, Guo X, Zheng Z, et al. Depression and anxiety in amyotrophic lateral sclerosis: correlations between the distress of patients and caregivers. Muscle Nerve. 2015;51(3):353-357.

9. Ng L, Khan F, Mathers S. Multidisciplinary care for adults with amyotrophic lateral sclerosis or motor neuron disease. Cochrane Database Syst Rev. 2009;(4):CD007425.

10. Miller RG, Jackson CE, Kasarskis EJ, et al. Practice parameter update: the care of the patient with amyotrophic lateral sclerosis: multidisciplinary care, symptom management, and cognitive/behavioral impairment (an evidence-based review): report of the Quality Standards Subcommittee of the American Academy of Neurology. Neurology. 2009; 73(15):1227-1233.

11. Jackson CE, McVey AL, Rudnicki S, Dimachkie MM, Barohn RJ. Symptom management and end-of-life care in amyotrophic lateral sclerosis. Neurol Clin. 2015;33(4):889-908.

12. Riemenschneider KA, Forshew DA, Miller RG. Multidisciplinary clinics: optimizing treatment for patients with amyotrophic lateral sclerosis. Neurodegen Dis Manage. 2013;3(2):157-167.

13. Aoun SM, Breen LJ, Howting D, et al. Receiving the news of a diagnosis of motor neuron disease: what does it take to make it better? Amyotroph Lateral Scler Frontotemporal Degener. 2016;17(3-4):168-178.

14. Aoun SM, Connors SL, Priddis L, Breen LJ, Colyer S. Motor neurone disease family carers' experiences of caring, palliative care and bereavement: an exploratory qualitative study. Palliat Med. 2012;26(6):842-850.

15. Hardiman O. Multidisciplinary care in ALS: measuring the immeasurable. Amyotroph Lateral Scler and Frontotemporal Degener. 2015; 16(Supp 1):S5.

16. Andersen PM, Abrahams S, Borasio GD, et al. EFNS guidelines on the clinical management of amyotrophic lateral sclerosis (MALS) - revised report of an EFNS task force. Eur J Neurol. 2012;19(3):360-375.

17. Miller RG, Jackson CE, Kasarskis EJ, et al. Practice parameter update: the care of the patient with amyotrophic lateral sclerosis: drug, nutritional, and respiratory therapies (an evidence-based review): report of the Quality Standards Subcommittee of the American Academy of Neurology. Neurology. 2009;73(15):1218-1226. 
18. Corr B, Frost E, Traynor BJ, Hardiman O. Service provision for patients with ALS/MND: a cost-effective multidisciplinary approach. J Neurol Sci. 1998;160(Suppl 1):S141-S145.

19. van Teijlingen ER, Friend E, Kamal AD. Service use and needs of people with motor neurone disease and their carers in Scotland. Health Soc Care Community. 2001;9(6):397-403.

20. Harris R, Abrams W. The International Alliances of ALS/MND Associations. Amyotroph Lateral Scler Other Motor Neuron Disord. 2003; 4(4):214-216.

21. Mayadev AS, Weiss MD, Distad BJ, Krivickas LS, Carter GT. The amyotrophic lateral sclerosis center: a model of multidisciplinary management. Phys Med Rehabil Clin N Am. 2008;19(3):619-631, xi.

22. Hogden A, Greenfield D, Nugus P, Kiernan MC. Development of a model to guide decision making in amyotrophic lateral sclerosis multidisciplinary care. Health Expect. 2015;18(5):1769-1782.

23. Guell MR, Anton A, Rojas-Garcia R, Puy C, Pradas J; en representacion de todo el grupo i. Comprehensive care of amyotrophic lateral sclerosis patients: a care model. Arch Bronconeumol. 2013;49(12):529-533.

24. Hardiman O, Traynor BJ, Corr B, Frost E. Models of care for motor neuron disease: setting standards. Amyotroph Lateral Scler Other Motor Neuron Disord. 2002;3(4):182-185.

25. NICE (National Institute for Health and Care Excellence). Motor neurone disease: assessment and management. Available from: https:// www.nice.org.uk/guidance/ng42. Published February 2016. Accessed January 27, 2017.

26. Marin B, Beghi E, Vial C, et al. Evaluation of the application of the European guidelines for the diagnosis and clinical care of amyotrophic lateral sclerosis (ALS) patients in six French ALS centres. Eur J Neurol. 2016;23(4):787-795.

27. Fullam T, Stephens HE, Felgoise SH, Blessinger JK, Walsh S, Simmons Z. Compliance with recommendations made in a multidisciplinary ALS clinic. Amyotroph Lateral Scler Frontotemporal Degener. 2015;17(1-2):30-37.

28. Borasio GD, Shaw PJ, Hardiman O, Ludolph AC, Sales Luis ML, Silani V; European ALS Study Group. Standards of palliative care for patients with amyotrophic lateral sclerosis: results of a European survey. Amyotroph Lateral Scler Other Motor Neuron Disord. 2001;2(3):159-164.

29. Van den Berg JP, Kalmijn S, Lindeman E, et al. Multidisciplinary ALS care improves quality of life in patients with ALS. Neurology. 2005;65(8):1264-1267.

30. Chio A, Bottacchi E, Buffa C, Mutani R, Mora G; PARALS. Positive effects of tertiary centres for amyotrophic lateral sclerosis on outcome and use of hospital facilities. J Neurol Neurosurg Psychiatry. 2006; 77(8):948-950.

31. Traynor BJ, Alexander M, Corr B, Frost E, Hardiman O. Effect of a multidisciplinary amyotrophic lateral sclerosis (ALS) clinic on ALS survival: a population based study, 1996-2000. J Neurol Neurosurg Psychiatry. 2003;74(9):1258-1261.

32. Rooney J, Byrne S, Heverin M, et al. A multidisciplinary clinic approach improves survival in ALS: a comparative study of ALS in Ireland and Northern Ireland. J Neurol Neurosurg Psychiatry. 2015;86(5):496-501.

33. Zoccolella S, Beghi E, Palagano G, et al. ALS multidisciplinary clinic and survival. Results from a population-based study in Southern Italy. J Neurol. 2007;254(8):1107-1112.

34. Dharmadasa T, Matamala JM, Kiernan MC. Treatment approaches in motor neurone disease. Curr Opin Neurol. 2016;29(5):581-591.

35. Bede P, Hardiman O, O'Brannagain D. An integrated framework of early intervention palliative care in motor neurone disease as a model for progressive neurodegenerative diseases. Poster presented at: 7 th European ALS Congress; May 22-24, 2009; Turin, Italy.

36. Hardiman O. Multidisciplinary care in motor neurone disease. In: Kiernan MC, editor. The Motor Neurone Disease Handbook. Sydney, Australia: MJA Books; 2007:164-174.

37. Collins A. Measuring What Really Matters. Towards a Coherent Measurement System to Support Person-Centred Care. London: The Health Foundation; 2014

38. Hogden A. Optimizing patient autonomy in amyotrophic lateral sclerosis: inclusive decision-making in multidisciplinary care. Neurodegener Dis Manag. 2014;4(1):1-3.
39. Foley G, Timonen V, Hardiman O. Patients' perceptions of services and preferences for care in amyotrophic lateral sclerosis. A review. Amyotroph Lateral Scler. 2012;13(1):11-24.

40. Aoun SM, Bentley B, Funk L, Toye C, Grande G, Stajduhar KJ. A 10 -year literature review of family caregiving for motor neurone disease: moving from caregiver burden studies to palliative care interventions. Palliat Med. 2013;27(5):437-446.

41. Creemers H, de Moree S, Veldink JH, Nollet F, van den Berg LH, Beelen A. Factors related to caregiver strain in ALS: a longitudinal study. J Neurol Neurosurg Psychiatry. 2016;87(7):775-781.

42. Bakker M, Creemers H, Schipper K, et al. Need and value of case management in multidisciplinary ALS care: a qualitative study on the perspectives of patients, spousal caregivers and professionals. Amyotroph Lateral Scler Frontotemporal Degener. 2015;16(3-4): 180-186.

43. Ewing G, Austin L, Diffin J, Grande G. Developing a person-centred approach to carer assessment and support. Br J Community Nurs. 2015; 20(12):580-584.

44. Aoun SM, Breen LJ, Oliver D, et al. Family carers' experiences of receiving the news of a diagnosis of motor neurone disease: a national survey. J Neurol Sci. 2017;372:144-151.

45. Aoun S, Deas K, Toye C, Ewing G, Grande G, Stajduhar K. Supporting family caregivers to identify their own needs in end-of-life care: qualitative findings from a stepped wedge cluster trial. Palliat Med. 2015;29(6):508-517.

46. Hogden A, Greenfield D, Nugus P, Kiernan MC. What are the roles of carers in decision-making for amyotrophic lateral sclerosis multidisciplinary care? Patient Prefer Adherence. 2013;7:171-181.

47. Zoing M. Motor neurone disease: a nurse's perspective. In: Kiernan MC, editor. The Motor Neurone Disease Handbook. Sydney, Australia: MJA Books; 2007:175-185.

48. Paganoni S, Karam C, Joyce N, Bedlack R, Carter GT. Comprehensive rehabilitative care across the spectrum of amyotrophic lateral sclerosis. NeuroRehabilitation. 2015;37(1):53-68.

49. Majmudar S, Wu J, Paganoni S. Rehabilitation in amyotrophic lateral sclerosis: why it matters. Muscle Nerve. 2014;50(1):4-13.

50. Oliver D, Aoun S. What palliative care can do for motor neurone disease and their families. Eur J Palliat Care. 2013;20(6):286-289.

51. Bede P, Oliver D, Stodart J, et al. Palliative care in amyotrophic lateral sclerosis: a review of current international guidelines and initiatives. J Neurol Neurosurg Psychiatry. 2011;82(4):413-418.

52. Oliver D, Borasio GD, Johnston W, editors. Palliative Care in Amyotrophic Lateral Sclerosis. From Diagnosis to Bereavement. 3rd ed. Oxford: Oxford University Press; 2014.

53. Oliver D, Watson S. Multidisciplinary care. In: Oliver D, editor. End of Life Care in Neurological Disease. London: Springer; 2012:113-132.

54. Oliver DJ, Borasio GD, Caraceni A, et al. A consensus review on the development of palliative care for patients with chronic and progressive neurological disease. Eur J Neurol. 2016;23(1):30-38.

55. Connolly S, Galvin M, Hardiman O. End-of-life management in patients with amyotrophic lateral sclerosis. Lancet Neurol. 2015;14(4): $435-442$.

56. van der Steen I, van den Berg JP, Buskens E, Lindeman E, van den Berg LH. The costs of amyotrophic lateral sclerosis, according to type of care. Amyotroph Lateral Scler. 2009;10(1):27-34.

57. Connolly S, Heslin C, Mays I, Corr B, Normand C, Hardiman O. Health and social care costs of managing amyotrophic lateral sclerosis (ALS): an Irish perspective. Amyotroph Lateral Scler Frontotemporal Degener. 2015;16(1-2):58-62.

58. Lopez-Bastida J, Perestelo-Perez L, Monton-Alvarez F, Serrano-Aguilar P, Alfonso-Sanchez JL. Social economic costs and health-related quality of life in patients with amyotrophic lateral sclerosis in Spain. Amyotroph Lateral Scler. 2009;10(4):237-243.

59. Deloitte Access Economics 2015, Economic analysis of motor neurone disease in Australia, report for Motor Neurone Disease Australia, Deloitte Access Economics, Canberra, November. Available from http://www. mndaust.asn.au/Influencing-policy/Economic-analysis-of-MND-(1)/ Economic-analysis-of-MND-in-Australia.aspx. Accessed March 30, 2017 
60. Oh J, An JW, Oh SI, et al. Socioeconomic costs of amyotrophic lateral sclerosis according to staging system. Amyotroph Lateral Scler Frontotemporal Degener. 2015;16(3-4):202-208.

61. Gladman M, Dharamshi C, Zinman L. Economic burden of amyotrophic lateral sclerosis: a Canadian study of out-of-pocket expenses. Amyotroph Lateral Scler Frontotemporal Degener. 2014;15(5-6):426-432.

62. Boylan K, Levine T, Lomen-Hoerth C, et al; ALS Center Cost Evaluation W/Standards \& Satisfaction (Access) Consortium. Prospective study of cost of care at multidisciplinary ALS centers adhering to American Academy of Neurology (AAN) ALS practice parameters. Amyotroph Lateral Scler Frontotemporal Degener. 2015;17(1-2):119-127.

63. Galvin M, Madden C, Maguire S, et al. Patient journey to a specialist amyotrophic lateral sclerosis multidisciplinary clinic: an exploratory study. BMC Health Serv Res. 2015;15:571.

64. Turner MR, Scaber J, Goodfellow JA, Lord ME, Marsden R, Talbot K. The diagnostic pathway and prognosis in bulbar-onset amyotrophic lateral sclerosis. J Neurol Sci. 2010;294(1-2):81-85.

65. Gladman M, Zinman L. The economic impact of amyotrophic lateral sclerosis: a systematic review. Expert Rev Pharmacoecon Outcomes Res. 2015;15(3):439-450.

66. Paganoni S, Macklin EA, Lee A, et al. Diagnostic timelines and delays in diagnosing amyotrophic lateral sclerosis (ALS). Amyotroph Lateral Scler Frontotemporal Degener. 2014;15(5-6):453-456.

67. Househam E, Swash M. Diagnostic delay in amyotrophic lateral sclerosis: what scope for improvement? J Neurol Sci. 2000;180(1-2):76-81.

68. O'Brien MR, Whitehead B, Jack BA, Mitchell JD. From symptom onset to a diagnosis of amyotrophic lateral sclerosis/motor neuron disease (ALS/MND): experiences of people with ALS/MND and family carers - a qualitative study. Amyotroph Lateral Scler. 2011;12(2): 97-104.

69. Mitchell JD, Callagher P, Gardham J, et al. Timelines in the diagnostic evaluation of people with suspected amyotrophic lateral sclerosis (ALS)/ motor neuron disease (MND) - a 20-year review: can we do better? Amyotroph Lateral Scler. 2010;11(6):537-541.

70. Callagher P, Mitchell D, Bennett W, Addison-Jones R. Evaluating a fasttrack service for diagnosing MND/ALS against traditional pathways. Br J Neurosci Nurs. 2009;5(7):322-325.

71. Motor Neurone Disease Association. [webpage on the Internet]. Red Flag diagnosis tool; 2014. Available from: http://www.mndassociation. org/forprofessionals/information-for-gps/diagnosis-of-mnd/red-flagdiagnosis-tool/. Accessed January 5, 2017.

72. Aoun SM, Breen LJ, Edis R, et al. Breaking the news of a diagnosis of motor neurone disease: a national survey of neurologists' perspectives. J Neurol Sci. 2016;367:368-374.

73. O'Brien M, Whitehead B, Jack B, Mitchell JD. Multidisciplinary team working in motor neurone disease: patient and family carer views. $\mathrm{Br}$ J Neurosci Nurs. 2011;7(4):580-585.

74. ALS Centrum Nederland [webpage on the Internet]. Over het ALS Centrum [updated 2017]. Available from: http://www.als-centrum.nl/ over-het-als-centrum. Accessed February 17, 2017.

75. Stephens HE, Felgoise S, Young J, Simmons Z. Multidisciplinary ALS clinics in the USA: a comparison of those who attend and those who do not. Amyotroph Lateral Scler Frontotemporal Degener. 2015;16(3-4): 196-201.

76. Stephens HE, Young J, Felgoise SH, Simmons Z. A qualitative study of multidisciplinary ALS clinic use in the United States. Amyotroph Lateral Scler Frontotemporal Degener. 2015;17(1-2):55-61.

77. Hobson EV, Baird WO, Cooper CL, Mawson S, Shaw PJ, McDermott CJ. Using technology to improve access to specialist care in amyotrophic lateral sclerosis: a systematic review. Amyotroph Lateral Scler Frontotemporal Degener. 2016;17(5-6):313-324.

78. Henderson RD, Hutchinson N, Douglas JA, Douglas C. Telehealth for motor neurone disease. Med J Aust. 2014;201(1):31.
79. Vitacca M, Comini L, Assoni G, et al. Tele-assistance in patients with amyotrophic lateral sclerosis: long term activity and costs. Disabil Rehabil Assist Technol. 2012;7(6):494-500.

80. Nijeweme-d'Hollosy WO, Janssen EP, Huis in 't Veld RM, Spoelstra J, Vollenbroek-Hutten MM, Hermens HJ. Tele-treatment of patients with amyotrophic lateral sclerosis (ALS). JTelemed Telecare. 2006;12(Suppl 1): S31-S34.

81. Zamarron C, Morete E, Gonzalez F. Telemedicine system for the care of patients with neuromuscular disease and chronic respiratory failure. Arch Med Sci. 2014;10(5):1047-1051.

82. Pinto A, Almeida JP, Pinto S, Pereira J, Oliveira AG, de Carvalho M. Home telemonitoring of non-invasive ventilation decreases healthcare utilisation in a prospective controlled trial of patients with amyotrophic lateral sclerosis. J Neurol Neurosurg Psychiatry. 2010;81(11):1238-1242.

83. Hogden A, Greenfield D, Caga J, Cai X. Development of patient decision support tools for motor neuron disease using stakeholder consultation: a study protocol. BMJ Open. 2016;6(4):e010532.

84. Oliver D, Campbell C, Sykes N, Tallon C, Edwards A. Decision-making for gastrostomy and ventilatory support for people with motor neurone disease: variations across UK hospices. J Palliat Care. 2011;27(3):198-201.

85. Oliver DJ, Turner MR. Some difficult decisions in ALS/MND. Amyotroph Lateral Scler. 2010;11(4):339-343.

86. Hogden A, Greenfield D, Nugus P, Kiernan MC. What influences patient decision-making in amyotrophic lateral sclerosis multidisciplinary care? A study of patient perspectives. Patient Prefer Adherence. 2012;6:829-838.

87. Hogden A, Greenfield D, Nugus P, Kiernan MC. Engaging in patient decision-making in multidisciplinary care for amyotrophic lateral sclerosis: the views of health professionals. Patient Prefer Adherence. 2012;6:691-701.

88. Creemers H, Veldink JH, Grupstra H, Nollet F, Beelen A, van den Berg LH. Cluster RCT of case management on patients' quality of life and caregiver strain in ALS. Neurology. 2014;82(1):23-31.

89. Goldstein LH, Abrahams S. Changes in cognition and behaviour in amyotrophic lateral sclerosis: nature of impairment and implications for assessment. Lancet Neurol. 2013;12(4):368-380.

90. Roggenbuck J, Quick A, Kolb SJ. Genetic testing and genetic counseling for amyotrophic lateral sclerosis: an update for clinicians. Genet Med. 2016;19(3):267-274.

91. Chio A, Battistini S, Calvo A, et al. Genetic counselling in ALS: facts, uncertainties and clinical suggestions. J Neurol Neurosurg Psychiatry. 2014;85(5):478-485.

92. Wagner KN, Nagaraja H, Allain DC, Quick A, Kolb S, Roggenbuck J. Patients with amyotrophic lateral sclerosis have high interest in and limited access to genetic testing. J Genet Couns. Epub 2016 Oct 20.

93. Aho-Ozhan HE, Bohm S, Keller J, et al. Experience matters: neurologists' perspectives on ALS patients' well-being. J Neurol. Epub 2017 Jan 24.

94. Bromberg MB, Schenkenberg T, Brownell AA. A survey of stress among amyotrophic lateral sclerosis care providers. Amyotroph Lateral Scler. 2011;12(3):162-167.

95. Faull C, Rowe Haynes C, Oliver D. Issues for palliative medicine doctors surrounding the withdrawal of non-invasive ventilation at the request of a patient with motor neurone disease: a scoping study. BMJ Support Palliat Care. 2014;4(1):43-49.

96. Phelps K, Regen E, Oliver D, McDermott C, Faull C. Withdrawal of ventilation at the patient's request in MND: a retrospective exploration of the ethical and legal issues that have arisen for doctors in the UK. BMJ Support Palliat Care. Epub 2015 Sept 11.

97. Schellenberg KL, Schofield SJ, Fang S, Johnston WS. Breaking bad news in amyotrophic lateral sclerosis: the need for medical education. Amyotroph Lateral Scler Frontotemporal Degener. 2014;15(1-2):47-54.

98. Maddocks I, Brew B, Waddy H, Williams I. Palliative Neurology. Cambridge: Cambridge University Press; 2005. 


\section{Publish your work in this journal}

The Journal of Multidisciplinary Healthcare is an international, peerreviewed open-access journal that aims to represent and publish research in healthcare areas delivered by practitioners of different disciplines. This includes studies and reviews conducted by multidisciplinary teams as well as research which evaluates the results or conduct of such teams or health care processes in general. The journal covers a very wide range of areas and welcomes submissions from practitioners at all levels, from all over the world. The manuscript management system is completely online and includes a very quick and fair peer-review system. Visit http://www.dovepress.com/ testimonials.php to read real quotes from published authors.

Submit your manuscript here: https://www.dovepress.com/journal-of-multidisciplinary-healthcare-journal 